\title{
Meios contínuos em neurocirurgia vascular e neurorradiologia intervencionista. Parte I
}

\author{
Rogelio Iván Ortiz-Velázquez¹, Jose Guilherme Mendes Pereira Caldas², Jorge \\ Arturo Santos Franco ${ }^{1}$, Rodrigo Mercado Pimentel', Rogelio Revuelta ${ }^{1}$ \\ Escola Politécnica da Universidade de São Paulo. \\ Este trabalho foi realizado graças ao apoio da Fundação de Amparo à Pesquisa do \\ Estado de São Paulo (Fapesp) - Processo nº 2006/03977-1.
}

\section{RESUMO}

Os aneurismas e as placas de ateroma compartem não somente um elevado índice de morbimortalidade, como também sua localização. Isso sugere que fatores hemodinâmicos contribuam no seu desenvolvimento. A quantificação de forças hemodinâmicas é complicada, especialmente em vasos intracranianos; porém, avanços recentes em mecânica computacional têm permitido calcular sua magnitude e distribuição em modelos arteriais com ajuda de técnicas de dinâmica de fluidos computacionais. No entanto, a compreensão desses modelos e a verificação de sua validade e limitações dependem do conhecimento de seu desenho e dos parâmetros hemodinâmicos utilizados. Por outro lado, a determinação das propriedades mecânicas das paredes arteriais é crucial, não somente para a compreensão das alterações do sistema cardiovascular no tempo e das causas responsáveis que dão origem às lesões vasculares, bem como para a realização da angioplastia, o planejamento de pontes arteriais e a seleção de próteses endovasculares. Dessa forma, a mais importante contribuição que podemos obter do conhecimento da biomecânica, em geral, e da mecânica dos meios contínuos, em particular, se encontra no melhor entendimento da fisiologia. Nesta revisão, passamos pelos conceitos fundamentais utilizados na formulação dos problemas da mecânica dos meios contínuos, com ênfase na pesquisa biomecânica das lesões vasculares, no intuito de oferecer algumas definições que promovam a análise crítica dos resultados nesse campo.

\section{PALAVRAS-CHAVE}

Mecânica dos meios contínuos. Neurocirurgia. Neurorradiologia. Lesões vasculares.

\section{ABSTRACT}

Mechanics of continuous media in vascular neurosurgery and endovascular neuroradiological procedures

Cerebral aneurysms and atherosclerosis share not only a high rate of morbidity and mortality, but also its location. It suggests that hemodynamic factors contribute to their development. Quantification of hemodynamic forces is complicated, especially in intracranial arteries. However, recent advances in computational mechanics have allowed calculating the magnitude and distribution of these forces in arterial models with the help of techniques of computational fluid dynamics. However, the understanding of these models and verification of their validity and limitations depend on the knowledge of its design and hemodynamic parameters. Furthermore, the determination of mechanical properties of the arterial walls is crucial, not only for the understanding of the changes of the cardiovascular system in time and the causes of the injuries that they develop, as well as to the realization of angioplasty, planning of arterial bypass or the selection of endovascular prosthesis, for example. Thus, concepts on mechanics of continuous media are needed in the body of knowledge of all interested in cerebrovascular disease. In this review, we look the fundamental concepts used in the formulation of the problems of the mechanics of continuous media, focusing on biomechanics research of vascular lesions, in order to provide some definitions that promote the critical analysis of the results in this field. The most important contribution that we can get from the knowledge of biomechanics, in general, and from the mechanics of continuous media, in particular, is a better understanding of physiology.

\section{KEY WORDS}

Mechanics of continuous media. Neurosurgery. Neuroradiology. Vascular lesions.

1 Neurocirurgião.

2 Professor livre-docente do Departamento de Radiologia da Universidade de São Paulo (USP) e chefe do Serviço de Neurorradiologia Intervencionista do Hospital das Clínicas da USP. 


\section{Introdução}

\section{A biologia está incluída na ciência e a mecânica não está limitada à física. \\ Y. C. Fung}

A first course in continuum mechanics

No hemisfério ocidental, a aterosclerose representa a patologia emblemática do sistema cardiovascular. No Brasil, 80\% dos acidentes vasculares cerebrais são de tipo isquêmico e, conforme dados do Ministério da Saúde, representam a principal causa de morte. ${ }^{26,27}$ Aneurismas cerebrais e hemorragia subaracnoidea compartem com a doença aterosclerótica não somente o elevado índice de morbimortalidade, mas também sua localização preferencial (curvas e bifurcações arteriais). Isso sugere que forças hemodinâmicas, tal como o shear stress, ou sua distribuição espaço-temporal, contribuam no desenvolvimento dessas lesões ${ }^{18,46}$ e, em última instância, determinem sua localização, taxa de crescimento e ruptura. ${ }^{19,38}$

Ainda que a história natural dos aneurismas intracranianos seja desconhecida, ${ }^{4,5,8,16,17,38}$ sabe-se que fatores mecânicos participam de sua origem, crescimento e ruptura.$^{5,16,17}$ Forças hemodinâmicas contribuem para o enfraquecimento local da parede, ao passo que forças intramurais participam da estabilidade ou do crescimento do saco aneurismático e, finalmente, a ruptura ocorre quando as forças hemodinâmicas excedem a resistência da parede. ${ }^{16,17}$ Por outro lado, no desenvolvimento das lesões ateroscleróticas, a disfunção endotelial é um evento precoce $e^{24,31,34,42}$ e sabemos que o endotélio é sensível às forças hemodinâmicas..$^{6,724,34,37,42}$ Ele expressa diferentes genes e produz distintas moléculas, dependendo da magnitude e direção das forças induzidas

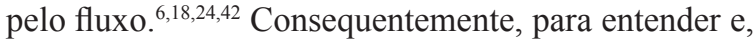
por último, controlar a função endotelial, em primeiro lugar há de se conhecer como o fluxo induz as forças que deformam as células, como as células reconhecem essas forças e como a transdução desses estímulos controlam a expressão gênica.

É possível comprovar que, sob tensão, os tecidos mudam sua morfologia, composição e taxa de crescimento. Assim, através do tempo existem variações da composição material e propriedades mecânicas em todo o sistema orgânico e essa é uma característica distintiva da vida. ${ }^{12}$ Particularmente, os vasos sanguíneos estão expostos a uma complexa distribuição de tensões que constituem estímulos que regulam proliferação, migração e apoptose, participando, portanto, do controle do crescimento e remodelamento vascular. ${ }^{24,33}$ Esse último é um fenômeno-chave no estudo do sistema vascular, pois transforma microestrutura, dimensões, funções, propriedades mecânicas e condiciona o desenvolvimen- to de lesões aneurismáticas e ateroscleróticas. ${ }^{11,17,18,42,46}$ Desse modo, podemos considerar aneurismas e placas de ateroma como exemplos clínicos nos quais o entendimento da mecânica arterial, particularmente do shear stress, é essencial para a neurocirurgia e ao procedimento endovascular.

Desde o ponto de vista físico, quando um fluido, como o sangue, é conduzido por intermédio de um tubo deformável, como uma artéria, interações entre as forças que regem a mecânica do fluido e as forças elásticas da parede geram ampla variedade de fenômenos, incluindo as relações não lineares pressão-fluxo, a propagação de ondas e a ressonância. ${ }^{11,13,17,20,31,41,43} \mathrm{O}$ entendimento da origem e da natureza desses fenômenos é ainda um desafio experimental, analítico e computacional formidável que envolve o estudo de fluxos instáveis a baixos números de Reynolds, interações fluxo-estrutura e análi-

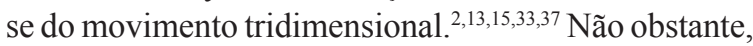
nossos conhecimentos vêm se modificando de tal modo que hoje temos a capacidade de visualizar tridimensionalmente a geometria do fluxo sanguíneo e a distribuição dos perfis de velocidade. ${ }^{1,2,8}$ Quer dizer, a aquisição de imagens detalhadas das bifurcações vasculares permitiu definir características locais do fluxo $0^{1,2,8,18,42,46}$ e ferramentas computacionais possibilitaram análises detalhadas das forças hemodinâmicas associadas ao desenvolvimento de lesões vasculares. ${ }^{23}$ Assim, não obstante a quantificação de forças hemodinâmicas ser complicada, especialmente em vasos intracranianos, avanços recentes em mecânica computacional têm permitido calcular a magnitude e distribuição dessas forças em modelos arteriais, com ajuda de técnicas de dinâmica de fluidos computacionais (CFD). ${ }^{9,22,38}$ Portanto, o aperfeiçoamento da angiografia rotacional 3D e a introdução do tratamento endovascular justificam, em parte, o crescimento do interesse pelos estudos de CFD, pois, teoricamente, é possível obter dados para a construção de ferramentas clínicas que auxiliem no planejamento do tratamento ou na determinação do risco de ruptura. ${ }^{4,5,21}$

No mesmo sentido, a determinação das propriedades mecânicas das paredes arteriais é crucial, não somente para a compreensão dos câmbios do sistema cardiovascular no tempo e das causas responsáveis que dão origem às lesões que nelas se desenvolvem, 5,11,12,16-18,46 bem como para a realização da angioplastia, o planejamento de pontes arteriais e a seleção de próteses endovasculares. , $, 9,15,21,22$ Por exemplo, pode-se comprovar que a proliferação da íntima, após implantação de um stent ou a realização de angioplastia por balão, é inibida por altos níveis de shear stress. ${ }^{41}$

Finalmente, novos métodos de mensuração, fundamentados na navegação endovascular, permitem hoje a mensuração de variáveis hemodinâmicas in situ e 
trouxeram consigo a necessidade de uma melhor análise dos dados, obrigando-nos a entender os fenômenos que somos capazes de mensurar. Por tudo isso, conceitos próprios da biomecânica ou, especificamente, da mecânica dos meios contínuos são cada vez mais necessários no conjunto de conhecimentos de todo interessado na patologia vascular cerebral. Nesta série de revisões, passamos pelos conceitos fundamentais utilizados na formulação dos problemas da mecânica dos meios contínuos, com ênfase na pesquisa biomecânica das lesões vasculares, no intuito de oferecer algumas definições que promovam a análise crítica dos resultados nesse campo.

Por alguma estranha razão que não compreendemos completamente, a natureza obedece à matemática.

Eli Passow

Understanding calculus concepts

Como forma de exemplificar nossa motivação, permitimo-nos introduzir alguns questionamentos básicos a respeito de asseverações aparentemente evidentes para todo neurocirurgião e neurorradiologista intervencionista.

"O sistema circulatório é um sistema de distribuição e intercâmbio que exemplifica a eficiência do desenho biomecânico. ${ }^{35,39}$ Descrita de maneira simples, a circulação consiste em uma bomba que força o sangue, periódica e ritmicamente, dentro de um sistema de tubos elásticos que se bifurcam. Os pulsos de pressão e fluxo viajam centrifugamente e são parcialmente refletidos nos pontos de mudança da impedância, dando origem a pulsos retrógrados, enquanto pulsos anterógrados são amortecidos ao alcançar os vasos de resistência. $O$ sangue, então, retorna num fluxo quase contínuo com pulsações secundárias impostas às veias pela contração muscular e pelo próprio coração. Por sua vez, uma árvore vascular típica está constituida por milhares de segmentos conectados em série e em paralelo, de diferentes diâmetros e comprimentos, e submetidos a diversas pressões e taxas de fluxo." Apesar dessa heterogeneidade morfológica e hemodinâmica, prevalece a hipótese de que seu desenho obedece a princípios físicos simples que otimizam a operação do sistema como um todo. ${ }^{25,28-}$ 30,32,35,36,39,44,45 Porém, como se definem esses princípios e as bases da otimização? E uma onda de pressão e fluxo? Por que aneurismas e placas de ateroma são lesões exclusivas do segmento convectivo da circulação?

O sistema cardiovascular é, desde logo, muito mais complexo que essa descrição sucinta, já que, por exemplo, apresenta geometria variável e viscoelasticidade não uniforme. ${ }^{11,12,14,17,23}$ Isso faz que soluções para problemas cardiovasculares e circulatórios dependam de descrições detalhadas e do uso de ferramentas analíticas que são, às vezes, estranhas e de difícil compreensão em função do tipo de formação que regularmente se espera de um médico.
Novamente, analisemos: "os vasos periféricos têm sido comumente vistos, desde o ponto de vista clínico, como responsáveis da pós-carga". ${ }^{31}$ Reconhecemos, então, o conceito que fundamenta o raciocínio clínico do tratamento da hipertensão arterial. Contudo, essa hipótese está fundamentada em condições de fluxo contínuo ${ }^{11,16,17,31} \mathrm{e}$, portanto, em paredes rígidas. Ademais, tanto artérias de distribuição (mediano calibre) como leitos vasculares periféricos contribuem à resistência. ${ }^{11,23}$ Assim, intuitivamente, parece que a natureza da descrição é inadequada, dado o caráter evidentemente pulsátil e, portanto, oscilatório da circulação, que se mantém inclusive pela microcirculação. ${ }^{23}$ Do mesmo modo, se considerarmos que "a impedância, diferentemente da resistência que se mantém constante, é uma variável complexa, cuja magnitude varia com a frequência de pulso", ${ }^{23}$ poderíamos nos questionar acerca do significado de uma variável complexa. A título de esclarecimento, o termo variável complexa refere-se a uma entidade matemática, baseada na manipulação de números complexos, sem relação com qualquer nível de dificuldade.

"O modelo Windkessel é o sistema acoplado de compliança-resistência mais utilizado para a descrição da natureza pulsátil da circulação". " Porém, meditemos acerca da seguinte afirmativa: "modelos baseados em segmentos arteriais viscoelásticos, de movimento livre, e fluxo governado por equações de Navier-Stokes constituem as melhores aproximações dos eventos circulatórios". ${ }^{45}$ Diante de ambos os modelos, podemos identificar suas diferenças? Existem diferenças? Podemos definir viscoelasticidade? E as equações de Navier-Stokes? Esses modelos têm clarificado o comportamento da parede arterial quando sujeita a variações de pressão e auxiliado no entendimento do estresse cíclico que atua sobre a parede e na forma como essa se adapta. Porém, o que é o estresse?

Assim, para cada modelo de descrição do sistema vascular é necessário verificar sua validade e limitações. ${ }^{1}$ Tais verificações dependem do conhecimento do desenho específico e dos parâmetros hemodinâmicos utilizados. Portanto, o entendimento da moderna teoria da circulação requer noções de mecânica dos meios contínuos que permitam uma adequada interpretação dos estudos que nela se desenvolvem. Finalmente, a mais importante contribuição que podemos obter do conhecimento da biomecânica, em geral, e da mecânica dos meios contínuos, em particular, encontra-se no melhor entendimento da fisiologia.

Devemos estar aptos, graças ao trabalho dos próprios matemáticos, a chegar a uma certeza no que diz respeito à maior parte das questões nas quais devemos nos preocupar; e, dentre essas, devemos ser capazes de encontrar 
a exata solução para problemas que, no passado, foram cobertos, por completo, pela tradicional incerteza...

Bertrand Russell

The principles of mathematics

No estudo de lesões vasculares, sejam aneurismas intracranianos ou placas de aterosclerose carotídeas, em algum momento teremos de definir conceitos como força, movimento, fluxo, deformação, propriedades materiais, interação entre corpos e mudanças de estado temporais ou permanentes etc. Afortunadamente, esses aspectos são suscetíveis de expressão matemática, na forma de equações diferenciais e condições de contorno, cuja solução oferece informação quantitativa do problema em estudo. ${ }^{10-12,16,17,23,43}$ Não propomos a discussão dos métodos de solução dessas equações. Nosso objetivo é oferecer definições que auxiliem na compreensão do processo que permite a expressão de um problema circulatório na sua forma matemática, pois desse modo se facilita a compreensão de sua natureza e a identificação das variáveis envolvidas, gerando, consequentemente, novos modelos e direções de pesquisa a partir de umas poucas suposições iniciais. Porém, dada a disparidade aparente entre as abordagens físico-matemática e médica, revisamos brevemente a história do desenvolvimento de alguns dos conceitos hemodinâmicos que hoje são de uso comum, para demonstrar que essa diferença é fictícia e que, por outro lado, procedimentos físico-matemáticos são muito mais que algoritmos para a resolução de problemas particulares. Geralmente, conceitos físicos e matemáticos são ideias profundas que têm um conjunto de aplicações tão amplo quanto seu tempo de evolução.

Galileu, estudante de medicina antes de se converter em físico, mostrou que a matemática é a chave da ciência, sem a qual, essa não pode ser adequadamente compreendida. Ele descreveu a constância do período do pêndulo, o que lhe permitiu mensurar pela primeira vez a frequência do pulso, ${ }^{31}$ e ainda contribuiu para a parte essencial da demonstração da existência da circulação que se baseou no seu princípio de medida. Harvey, discípulo de Galileu, foi o primeiro a notar que as válvulas do sistema cardiovascular permitem o fluxo unidirecional do sangue. Essa observação, em associação com o princípio da conservação da massa, levou-o a postular que o sangue retorna das artérias às veias. Ele mediu a capacidade ventricular e, sabendo a frequência de pulso, calculou o gasto cardíaco, obtendo um resultado de $234 \mathrm{~kg} / \mathrm{h}$. Obviamente, tal resultado, em função do princípio da conservação da massa, exigia a existência do fenômeno circulatório. O conceito da circulação de Harvey requeria, ademais, a existência teórica de capilares. A descoberta dos capilares, por Malpighi, 45 anos depois, ${ }^{11,23}$ somente corroborou uma necessidade lógica. Isso demonstra, como frequentemente ocorre, que a teoria (princípio de conservação da massa) motiva e guia os estudos experimentais. Por outro lado, Newton não fez estudos de biologia, porém seu cálculo, as leis do movimento e a equação constitutiva dos fluidos viscosos são os fundamentos para qualquer estudo do fluxo arterial. ${ }^{43}$

No século XVIII, foi notável o desenvolvimento do tratamento teórico da dinâmica dos fluidos, especificamente no campo dos fluidos ideais, nos quais o efeito da viscosidade é ignorado. O líder nesse campo foi médico e o mais prolífico matemático da história: Euler. Euler generalizou as leis do movimento de Newton em equações diferenciais parciais que deram origem à mecânica do contínuo e ao estabelecimento das equações de Navier-Stokes. ${ }^{10}$ Apesar de descrever as equações da propagação da onda de pulso, reconheceu a dificuldade de analisar tais fenômenos, não sendo capaz de encontrar sua solução. ${ }^{31}$

A dinâmica dos fluidos do século XIX se dividiu na luta entre os engenheiros que observaram o que não podia ser explicado e os matemáticos que explicaram o que não podia ser observado. ${ }^{16,17,31}$ Porém, aconteceram importantes avanços na teoria e aplicações. Um dos mais proeminentes se deve, uma vez mais, a um médico: Poiseuille. Ele logrou estabelecer, experimentalmente, a relação entre fluxo, gradiente de pressão e dimensões de um tubo capilar, mostrando que a taxa de fluxo se relaciona com a quarta potência do diâmetro interno do tubo. Seus resultados, por outro lado, permitiram o estabelecimento da mais famosa condição de contorno entre um fluido viscoso e a parede de um sólido: a condição de não deslizamento. ${ }^{43}$ Uma formação similar em medicina e física teve Thomas Young, ${ }^{19}$ cujas pesquisas biofísicas incluíram a visão humana e a percepção da cor. Porém, é conhecido por seu trabalho acerca da natureza da elasticidade, particularmente, das propriedades elásticas das artérias e da velocidade de propagação do pulso arterial. Seu trabalho levou ao conceito de módulo elástico (módulo de Young). ${ }^{11,12,16,17,23,31}$ Por seu turno, os irmãos Weber (um físico e o outro médico) estabeleceram muitas das propriedades das ondas de pulso propagadas e refletidas. ${ }^{31}$ Seus resultados e o trabalho de Young permitiram que Moens e Korteweg descrevessem matematicamente a relação entre a velocidade de pulso arterial e o módulo de elasticidade da parede arterial', até hoje a mais útil relação entre a propagação da onda de pulso e as propriedades da parede arterial. ${ }^{16,17,23,45}$

$$
C o=\sqrt{\frac{E h}{2 r p}}
$$

Nela, é possível reconhecer que a velocidade depende do módulo de elasticidade $(E)$ da artéria e da espessura da 
parede $(h)$ e varia de maneira inversamente proporcional ao raio interno da artéria $(r)$ e à densidade do sangue $(\rho)$. Assim, tal formulação é um exemplo de como a correlação de propriedades mecânicas e geométricas é útil na descrição do comportamento do mais básico dos sinais clínicos.

Por outro lado, o desenvolvimento do que hoje é a teoria biomecânica moderna teve de esperar até a conclusão da Segunda Guerra Mundial e o desenvolvimento da teoria dos fenômenos não lineares, ${ }^{10-12,16,17,23,31,43}$ sendo somente possível graças aos avanços em física e matemática aplicada, à introdução do computador digital e ao desenvolvimento de métodos numéricos (elementos finitos) que permitem explorar as capacidades computacionais.

Todavia, talvez o mais importante e fundamental avanço no estudo dos problemas circulatórios foi a demonstração por Womersley, McDonald e Taylor, após a introdução de uma aplicação da integral conhecida como transformada rápida de Fourier, da validez e aplicabilidade da análise de Fourier nos fenômenos circulatórios. ${ }^{31}$ Quer dizer, a representação do sistema arterial como um oscilador contínuo capaz de ser analisado no domínio da frequência. Considere-se, assim, que a regularidade do batimento cardíaco é uma das principais características do sistema cardiovascular. Sabemos também que normalmente essa regularidade é mantida durante longos períodos de tempo. Desse modo, tal qualidade do sistema cardiovascular caracteriza um estado de oscilação contínua. Nessa condição, qualquer onda, de pressão ou fluxo, que se repita regularmente pode ser representada por uma série de Fourier, isto é, a onda pode ser descrita como a soma de um conjunto de ondas cujas frequências são múltiplos inteiros da frequência de repetição da onda em estudo. ${ }^{15,41}$ A vantagem dessa abordagem é que seu tratamento matemático se facilita. Sem embargo, ao aplicar a análise de Fourier à circulação, certas simplificações têm de ser aceitas. A de maior importância depende da circulação não ser um sistema linear, de tal forma que, apesar de as séries de Fourier representarem o pulso de fluxo ou pressão, estritamente falando, não se pode dizer que um termo harmônico de pressão está relacionado diretamente com seu correspondente termo harmônico de fluxo. Porém, o efeito da não linearidade (calculado por Womersley) é suficientemente pequeno para se negligenciá-lo em uma primeira aproximação. ${ }^{31}$

\section{Definições}

A biomecânica provê as ferramentas físicas $e$ analíticas que permitem descrever os problemas fisiológicos com acurácia matemática. Y. C. Fung

Biomechanics: mechanical properties of living tissues
A abordagem matemática dos problemas circulatórios inicia-se com a ideia de aproximação. Imaginemos que não contamos com as ferramentas para resolver um problema. Assim, em lugar de tentar resolvê-lo de maneira exata, temporariamente nos mantemos satisfeitos com uma solução aproximada. Essa solução, então, é refinada de modo a oferecer melhor estimativa do problema. Logo, continuamos a melhorar a aproximação até alcançar a resposta esperada (limite). A ideia de aproximação é muito comum na vida diária, usamo-la quando tentamos encontrar uma palavra no dicionário ou determinar nosso peso. Em ambos os casos, nossa primeira aproximação é refinada diversas vezes, cada vez mais perto de nosso objetivo, até alcançarmos uma conclusão satisfatória (a palavra ou o peso correto). De maneira análoga, muitos dos problemas em matemática podem ser abordados mediante esses passos: aproximação, refinamento e limite. No mesmo sentido, as teorias científicas também constituem aproximações que descrevem situações físicas com certo grau de acurácia e são continuamente refinadas para uma maior exatitude.

A análise fundamentada em modelos matemáticos para descrever a evidência experimental e sua teoria é uma característica de inúmeras disciplinas científicas. Contudo, nas ciências médicas, a complexidade física e a inacessibilidade experimental dos sistemas biológicos têm limitado essa abordagem. ${ }^{23,31}$ Sem embargo, progressos em matemática analítica e computacional, o melhor entendimento dos sistemas biológicos e novas técnicas de imagem têm permitido o desenvolvimento de modelos que predizem o comportamento biológico em resposta a mudanças internas ou externas. ${ }^{40}$ No contexto particular do sistema vascular, o objetivo desses modelos é a predição acurada do ambiente mecânico das células que formam a parede arterial (mecânica dos sólidos) e do fluxo sanguíneo (mecânica dos fluidos), considerados determinantes maiores da homeostase do sistema. ${ }^{20}$

Já que a biomecânica e a mecânica dos meios contínuos proveem o marco teórico-matemático que permite a análise dos problemas do sistema vascular, ${ }^{10-13,15-17,20,23,31,33,40,43}$ começamos por defini-las.

\section{Biomecânica}

A biomecânica pode ser entendida, de maneira ampla, como o estudo da correlação entre a função de um sistema fisiológico e sua estrutura, a partir dos princípios que regem os eventos do universo físico. ${ }^{11,12,16,17} \mathrm{Seu}$ objetivo é o estudo da geometria, propriedades materiais e condições de contorno que permitam caracterizar a 
resposta dos sistemas biológicos, diante das mais diversas forças, facilitando o reconhecimento da influência que o mundo físico exerce na estrutura, propriedades e funções dos seres vivos. Assim, o campo de estudo da biomecânica abrange: a distribuição do estresse; o estabelecimento de equações constitutivas que descrevem as propriedades mecânicas dos materiais; a resistência e propriedades viscoelásticas (creep, histerese, fratura, fadiga, corrosão); os materiais compósitos; o fluxo; a transferência de calor e de massa (difusão e transporte por meio de membranas); o movimento de partículas (correntes iônicas etc.); a estabilidade e o controle dos sistemas mecânicos; a propagação de ondas; a vibração; as ondas de choque e a ressonância; entre outros.

Segundo Fung, ${ }^{11,12}$ existem quatro pré-requisitos para a solução de qualquer problema em biomecânica:

1. identificação da geometria ou estrutura do sistema;

2. identificação dos materiais e suas propriedades mecânicas;

3. identificação das leis básicas que governam o comportamento do sistema;

4. identificação das condições iniciais e de contorno.

Assim, o primeiro dos requisitos requer estudos anatômicos, histológicos e microestruturais dos corpos em análise (artérias, aneurismas, placas etc.), com a finalidade de conhecer sua configuração geométrica. $\mathrm{O}$ segundo envolve ensaios mecânicos, no intuito de formular equações constitutivas. Essas relacionam o estresse ao estiramento e à taxa de deformação, quer dizer, definem o comportamento mecânico do material do qual está constituído o corpo e são, normalmente, determinadas por uma combinação de experimentação e estudos teóricos (limites termodinâmicos). Esse passo é frequentemente difícil, pois, em geral, não é possível isolar o tecido para testá-lo. Ainda, o tamanho da amostra pode ser muito pequeno ou podem existir dificuldades para manter o tecido em condições fisiológicas. Por outro lado, com frequência, as relações estresse-deformação em amostras biológicas são não lineares e a não linearidade faz a determinação das equações constitutivas um reto. Apesar disso, é possível estabelecer sua forma matemática, fazendo uso de parâmetros (incógnitas), cujo valor pode ser determinado posteriormente, mediante experimentação. $\mathrm{O}$ terceiro depende do número de hipóteses assumidas e do grau de simplificação do problema. No entanto, deverão ser satisfeitos os axiomas da mecânica do contínuo: leis do movimento (Newton), leis de conservação (massa, momento e energia) e as equações constitutivas dos materiais. Qualquer outra hipótese $a d$ hoc deverá ser especificada e tratada com precaução no tocante a sua validade. Com a informação básica (equações constitutivas) e os princípios adequadamente ordenados (leis de movimento etc.), é possível construir as equações governantes que regem o problema. Por último, a identificação das condições iniciais e de contorno depende do tipo de problema. Logo, o conhecimento do ambiente no qual o sistema trabalha é indispensável para sua caracterização, pois as condições de contorno não são mais que os fatos conhecidos que caracterizam o problema. Por ser esse um dos conceitos fundamentais, passamos a esclarecer seu significado, exemplificando a condição de contorno mais importante no estudo da circulação arterial.

Considere que, como consequência da viscosidade de um fluido, não possam existir câmbios abruptos da velocidade em qualquer ponto de um campo de fluxo. Então, na interface de um fluido (fluxo de sangue) e sua fronteira sólida (parede arterial), a velocidade do fluido (velocidade do sangue em contato com a parede) deverá ser a mesma que a velocidade da fronteira (parede arterial), pois de outra maneira existiria uma mudança súbita de velocidade nesse ponto. Essa condição é denominada condição de contorno de não deslizamento (no-slip boundary condition) e deverá ser satisfeita em toda análise de fluxos viscosos. ${ }^{43}$ Isso significa que nas artérias, por exemplo, o sangue não pode simplesmente escorregar. Em vez disso, o sangue em contato com a parede arterial não se move, pois deve ter a mesma velocidade da parede, que se mantém estática. Entretanto, as camadas de fluxo que se separam da parede movem-se com velocidades que crescem ao aumentar a distância à mesma. Portanto, ao conectar a velocidade máxima do centro da luz arterial à velocidade zero na parede, forma-se um perfil parabólico sem câmbios abruptos de velocidade em todos os pontos do campo (perfil parabólico do fluxo laminar). Essa condição é a razão pela qual se requer a ação de bomba do coração para manter o fluxo. Na sua ausência, o fluido seria capaz de escorregar e manter-se em um estado de fluxo contínuo, sem gasto de energia. Na sua presença, o trabalho cardíaco é requerido para manter o gradiente de velocidade com respeito à parede arterial.

Por outro lado, os corpos, que regularmente se estudam nas teorias clássicas de hidrodinâmica e elasticidade, têm geometria simples ou ao menos conhecida. As equações constitutivas têm sido provadas e suas condições de contorno identificadas. Em contraste, os problemas em biomecânica não somente fogem das teorias clássicas da elasticidade e hidrodinâmica, bem como sua principal dificuldade encontra-se na ausência de dados que permitam o estabelecimento das equações constitutivas. ${ }^{11,12,23}$ Contudo, uma vez formulado o problema, resta encontrar soluções para as equações 
governantes, com condições iniciais e de contorno apropriadas. A solução pode ser analítica, numérica (elementos finitos) ou experimental. Porém, a realização de experimentos que confirmem as soluções encontradas sempre é necessária, pois comparar os resultados experimentais com os resultados teóricos e numéricos é a única forma de justificar a validade das hipóteses. ${ }^{1}$ Se estudos analíticos e numéricos são representativos dos achados experimentais, quer dizer, se for possível corroborar a concordância, então estaremos em capacidade de calcular os valores numéricos dos coeficientes indeterminados (parâmetros) presentes nas equações constitutivas. Se as novas equações obtidas predisserem com acurácia o comportamento de outros problemas, então a validade está provada e, somente depois disso, o método poderá ser utilizado para explorar sua utilidade prática e experimental.

\section{Mecânica do contínuo}

$\mathrm{Na}$ escala de observação natural (macroscópica) podemos pensar, por exemplo, em qualquer líquido como um meio contínuo (sem descontinuidades, buracos ou fissuras).$^{43} \mathrm{Na}$ realidade, porém, os líquidos são coleções de moléculas discretas que apresentam espaços entre elas. Para o estudo de seu comportamento, a mecânica clássica oferece basicamente duas abordagens: a mecânica do contínuo e a mecânica estatística. A mecânica estatística descreve o comportamento médio de cada molécula individual para entender o desempenho global do meio em escala macroscópica. Na mecânica do contínuo, por outra parte, considera-se um volume de comportamento médio, independentemente de qualquer atenção às moléculas individuais. ${ }^{10}$

Matematicamente, os objetos físicos (corpos materiais) podem ser tratados como meios contínuos limitados por uma superfície fechada. A superfície pode ser real, como a pele que limita o corpo humano. Porém, pode ser imaginária, como no caso de uma superfície encerrando um lugar do espaço tridimensional. Sabe-se que os objetos físicos estão sujeitos a forças externas atuando em seus corpos, como ocorre com a gravidade (forças de volume ou de campo), e em suas superfícies, como a pressão atmosférica (forças de superfície ou de contato). Se considerarmos esses corpos como meios contínuos, então será possível conhecer a forma como eles reagem a essas forças. Assim, a determinação das condições internas do corpo, em resposta às forças externas, é o campo de estudo da mecânica do contínuo. ${ }^{10}$ Quer dizer, essa abrange o comportamento dos sólidos e fluidos em uma escala na qual as suas propriedades físicas (massa, momento, energia, velocidade, acelera- ção, tensão, estiramento, deformação etc.) podem ser definidas para cada ponto do corpo. ${ }^{12,16,43}$

Porém, o que é um ponto do corpo material? Imaginemos, por exemplo, um líquido como a água. Acreditemos que essa está constituída de pequenas partes, todas elas contínuas umas com as outras, sem espaços vazios entre elas, e as denominemos elementos do fluido (tal como gotas que quando unidas formam um corpo de água). Convenhamos agora que cada elemento do fluido (cada gota) é excessivamente grande para a escala microscópica e infinitamente pequeno para a escala macroscópica. A primeira condição é necessária para assegurar que cada elemento (cada gota) contenha uma quantidade grande de moléculas do líquido, que garantam seu comportamento como tal, e a segunda é indispensável para tratar cada elemento do fluido como um ponto da escala macroscópica. Eis um exemplo, considere um milímetro cúbico de ar. Ele contém $10^{16}$ moléculas. Se definirmos um elemento de ar como o volume de uma milionésima parte do milímetro cúbico, esse elemento ainda estará constituído de $10^{10}$ moléculas; isso ainda é excessivamente grande para a escala microscópica, assegurando que o elemento se comporte como o ar, porém suficientemente pequeno para que uma milionésima parte do milímetro cúbico possa ser tratada como um ponto na escala macroscópica (Figura 1).

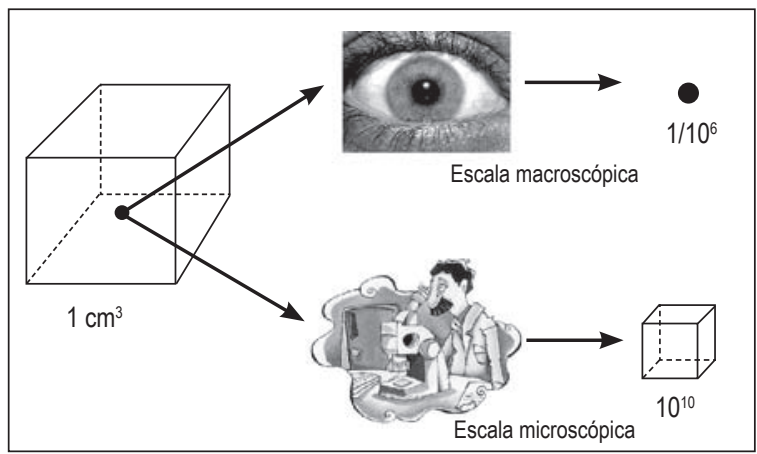

Figura 1-Definição de ponto em um meio contínuo.

Generalizemos a ideia anterior. O tratamento de um corpo material como um meio contínuo é razoavelmente aplicado quando a relação $\boldsymbol{\delta} / \boldsymbol{\lambda}<<\mathbf{1},{ }^{43}$ onde $\boldsymbol{\delta}$ é a escala da microestrutura e $\lambda$ é a escala do problema físico de interesse. Se se estiver interessado nas forças às quais células endoteliais estão submetidas secundariamente ao fluxo, a escala é de $\boldsymbol{\mu m}$ para as células endoteliais (microestrutura) e $\mathbf{m m}$ para o problema físico (parede arterial). Portanto, a relação $\delta / \lambda$ é $\boldsymbol{\mu m} / \mathbf{m m} \approx \mathbf{0 , 0 0 1}$, o que torna a hipótese do contínuo uma proposta razoável. De maneira similar, se o interesse recair na velocidade 
da parte central do fluxo em uma artéria, a escala, uma vez mais, é de $\boldsymbol{\mu} \mathbf{m}$ para a microestrutura (diâmetro das células vermelhas) e de $\mathbf{m m}$ para o problema físico (diâmetro arterial), assim $\delta / \lambda<1$. Contudo, essa situação difere no capilar, onde $\boldsymbol{\delta} / \boldsymbol{\lambda} \approx \mathbf{1}$, já que os diâmetros do eritrócito e capilar são aproximadamente iguais (5-8 $\mu \mathrm{m})$. Portanto, nesse caso a hipótese do contínuo não resulta aplicável. Assim, a pertinência de uma abordagem fundamentada na hipótese do contínuo dependerá do desenho experimental.

Como mencionado, sob a hipótese do contínuo é possível definir propriedades locais para cada ponto do corpo e encontrar as quantidades físicas de interesse (estresse, deformação etc.) também para cada ponto. Isso indica, por outra parte, que as equações governantes do problema são equações de ponto, tendo, portanto, de ser resolvidas para cada ponto do corpo. Para exemplificar a importância do anterior, pensemos no problema do fluxo sanguíneo. A condição de não deslizamento parece contrariar a evidência experimental de que, na circulação, estase sanguínea é sinônimo de trombose. Contudo, o conflito se resolve ao reconhecer que a condição de contorno é uma condição de ponto e, portanto, um eritrócito ou uma plaqueta, por exemplo, estão em repouso no ponto em que eles interagem com a parede, satisfazendo a condição. Todavia, somente naquele ponto o repouso é uma condição. O resto da superfície, constituída de inúmeros pontos em movimento, provoca seu deslocamento (o rolling observado na microscopia intravital) e, consequentemente, não existe contradição entre a condição de não deslizamento e os princípios de Virchow. Por outro lado, resulta evidente a necessidade de técnicas de cômputo para a resolução desse tipo de problema, pois é possível contar os pontos do corpo por milhares ou milhões.

Passemos agora a alguns aspectos formais. O conceito de contínuo deriva da matemática. ${ }^{10}$ Nessa, o sistema dos números reais é um contínuo, pois entre quaisquer dois números reais (diferentes) que escolhamos existe uma infinidade de outros números reais que preenchem o intervalo da reta numérica, limitado pelos números inicialmente considerados, sem que existam descontinuidades ou buracos. Intuitivamente, o tempo é um contínuo e, por isso, pode ser representado por um sistema de números reais, pois é possível encontrar para cada instante do tempo um instante precedente e outro subsequente que preencham a linha do tempo, como os números reais preenchem a reta numérica. Da mesma maneira, o espaço tridimensional pode ser representado por um contínuo constituído de trios ordenados de números reais $(\mathrm{x}, \mathrm{y}, \mathrm{z})$. Assim, definir um problema, que varia no espaço e no tempo, é definir um problema do contínuo tetradimensional.
Estendendo o conceito do contínuo à matéria, podemos definir a distribuição contínua da matéria no espaço mediante o conceito de densidade. Considerando que a quantidade de matéria é medida pela massa e assumindo que certa quantidade de matéria ocupa certo espaço $V_{\mathrm{o}}$, escolhemos um ponto $\mathrm{P}$ qualquer do espaço $V_{\mathrm{o}}$ e definimos uma sequência de subespaços progressivamente menores de $V_{\text {o }}$ que se acercam ou convergem em $\mathrm{P}$ e que denominamos $V_{l}, V_{2}, V_{3}, \ldots V_{n-1}, V_{n}$ (Figura 2).

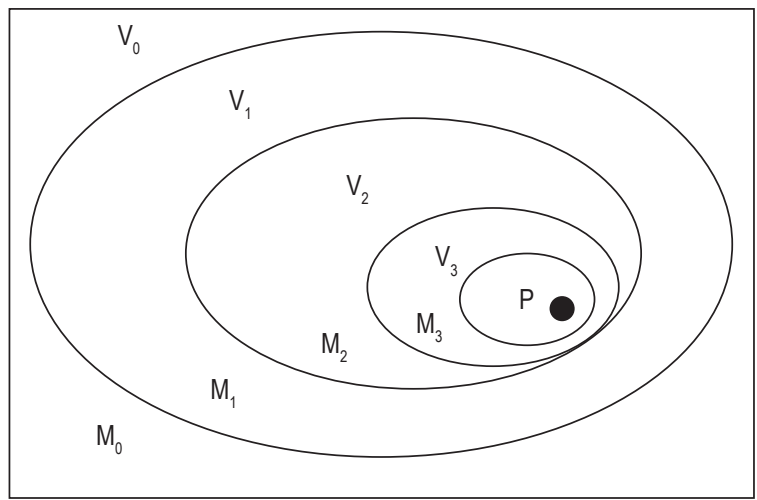

No espaço ocupado por $V_{0}$, a sequência de subespaços $V_{1}, V_{2}, V_{3}, \ldots V_{n-1}, V_{n}$ que convergem no ponto $(P)$ permite definir a série de razões $M_{0} / V_{0}, M_{1} / V_{1}, M_{2} / V_{2}, \ldots$ $\mathbf{M}_{n-1} / \mathbf{V}_{n-1}, \mathbf{M}_{n} / \mathbf{V}_{n}$ entre a massa (M) e o volume (V) de cada subespaço. No limite, quando o número de subespaços cresce indefinidamente $\left(V_{n} \rightarrow \infty\right)$, a razão $\mathrm{Mn} / \mathrm{Vn}$ define a densidade de massa no ponto $(\mathrm{P})$.

Figura 2 - Conceito de densidade em um meio contínuo.

Se chamarmos o volume de $V_{n}$ como $\mathbf{V}_{\mathrm{n}}$, e a massa da matéria contida em $V_{n}$ como $\mathbf{M}_{\mathrm{n}}$, podemos formar a razão $\mathbf{M}_{\mathbf{n}} / \mathbf{V}_{\mathbf{n}}$ à qual denominamos densidade. Continuemos a fazer que $V_{n}$ se aproxime de P progressivamente, fazendo $\mathbf{V}_{\mathbf{n}}$ infinitas vezes menor até que seu valor seja próximo de zero. Esse processo, denominado passo ao limite, gera um valor (limite) da densidade que chamamos densidade da distribuição de massa no ponto $P$ e que, abreviadamente, pode-se escrever como $\boldsymbol{\rho}(\mathrm{P})$. Se a densidade pode ser definida dessa maneira, em qualquer ponto de $V_{\mathrm{o}}$ a massa estará distribuída de maneira contínua. Uma abordagem similar é usada para definir a densidade de momento e de energia. Assim, um material, um corpo, um meio é um contínuo se a densidade de massa, de momento e de energia existirem nesse sentido matemático. Sem embargo, essa definição matemática do contínuo não pode ser satisfeita por sistemas do mundo real. ${ }^{10}$ Por exemplo, um gás não satisfaz a condição matemática de um meio contínuo se $V_{n}$ se tornar menor que a distância média entre as moléculas. Da mesma forma, nenhum organismo, tecido ou célula pode satisfazer o critério matemático do contínuo. Por isso, Fung ${ }^{10-12}$ propõe uma definição do meio contínuo similar ao conceito matemático, exceto pelo tamanho permitido de $V_{n}$, o qual nunca pode ser 
menor que o tamanho das partículas das quais está constituído o material.

Uma vez que se decidiu que um corpo material (sólido ou fluido) pode ser descrito como um contínuo, é possível realizar uma cópia geométrica abstrata, no sentido matemático da definição do contínuo, quer dizer, uma cópia isomórfica em relação ao sistema dos números reais. Isso significa que cada ponto do corpo corresponde a um ponto do espaço euclidiano, que é identificado mediante um e somente um trio $(\mathrm{x}, \mathrm{y}, \mathrm{z}) \mathrm{de}$ números reais, formando-se uma cópia ideal do corpo no espaço tridimensional (Figura 3). Essa idealização da matéria tem as seguintes características:

- A densidade de massa do sistema idealizado é a mesma que a do sistema real.

- O conjunto de forças aplicadas em ambos os sistemas (ideal e real) gera o mesmo estresse e deformação.

- As equações constitutivas do sistema real são utilizadas para descrever as propriedades mecânicas do sistema ideal.

- O sistema real satisfaz as equações de movimento, continuidade e balanço da energia do sistema ideal com erros cujos limites podem ser calculados.

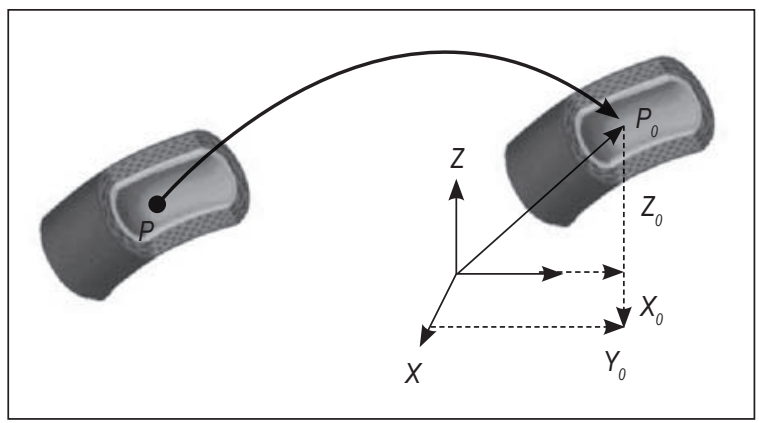

Em uma cópia isomórfica em relação aos números reais, cada ponto do corpo (p) corresponde a um ponto (Po) do espaço tridimensional que, por sua vez, é identificado pelas suas coordenadas (Xo, Yo, Zo).

Figura 3 - Cópia ideal de um meio contínuo.

A vantagem de idealizar o corpo se encontra na facilidade de cálculo, pois a determinação de estresse e deformações pode realizar-se de maneira rigorosa na cópia isomórfica. Entretanto, no corpo real há limitações experimentais de tamanho e variabilidade estatística que, por outra parte, sempre deverão ser avaliadas. ${ }^{31}$

Por outro lado, tratando de equações constitutivas, se essas forem as mesmas para valores consecutivos de tamanho do corpo, então, a cópia abstrata tem somente uma equação constitutiva em todas as escalas de tamanho. De maneira recíproca, se as equações constitutivas do corpo são diferentes para diferentes intervalos de valores de tamanho, então a cópia abstrata também tem diferentes equações constitutivas para esses mesmos valores de tamanho. Essa é uma característica útil, pois permite estudar diferentes estruturas do corpo e seu comportamento em diferentes dimensões de observação, o que facilita o entendimento das partes e do todo. Essa hierarquia nas equações constitutivas está relacionada ao grau de similaridade da estrutura do corpo em todos os seus níveis. Por exemplo, a estrutura geométrica do material pode ser fractal, quer dizer, autossimilar em sucessivos limites de valores do tamanho ou, pelo contrário, ser completamente aleatória. Se considerarmos o padrão geométrico das vias aéreas dos grandes brônquios até os pequenos bronquíolos, a estrutura é fractal e pode-se esperar que os bronquíolos obedeçam às mesmas equações constitutivas. Porém, o padrão alveolar não é fractal e as propriedades mecânicas dessa escala necessitam de descrições completamente diferentes. Assim, a escala de observação muda não somente a aparência do objeto, como também seu comportamento e, dependendo da propriedade que se deseja pesquisar, é possível considerar o corpo de estudo com diferentes hierarquias constitutivas.

Finalmente, mencionaremos que a mecânica do contínuo tem como axiomas os mesmos da física (leis do movimento de Newton, leis de conservação etc.). ${ }^{10-12,16,17,23,31,45}$ Porém, existem três axiomas adicionais, próprios da mecânica do contínuo:

- Em um corpo ou meio contínuo, duas partículas que são vizinhas em um período de tempo se mantêm vizinhas em todos os tempos. É importante notar que isso não significa que o corpo não possa fraturar-se ou dividir-se. Porém as superfícies de fratura ou de divisão se convertem em novas superfícies externas. Assim, nos organismos o crescimento ou a reabsorção tissular que incrementam ou diminuem a massa criam novas superfícies no corpo.

- O estresse e a deformação podem ser definidos em qualquer ponto do corpo.

- $\mathrm{O}$ estresse em um ponto está relacionado à deformação e à velocidade de deformação no mesmo ponto. Entretanto, a relação de estressedeformação é influenciada por outros parâmetros como temperatura, carga elétrica etc. Não obstante, esses podem ser estudados de maneira independente.

\section{Estresse}

Voltemos ao conceito de densidade material e reconsideremos o ponto $\mathrm{P}$ no espaço $V_{o}$ e a mesma sequência de subespaços $V_{1}, V_{2}, V_{3}, \ldots V_{n-l}^{o}, V_{n}$ em $V_{o}$ com seus 
volumes correspondentes $\mathrm{V}_{1}, \mathbf{V}_{2}, \mathbf{V}_{3}, \ldots \mathbf{V}_{\mathrm{n}-1}, \mathbf{V}_{\mathrm{n}}$, cada um envolvendo P (Figura 2). Assim, segundo Fung, ${ }^{10}$ quando o número de subespaços cresce e tende ao infinito $(\mathrm{n} \rightarrow \infty)$, o valor de $\mathbf{V}_{\mathrm{n}}$ se aproxima de um valor $\boldsymbol{\omega}$ e a sequência das sucessivas razões $\mathbf{M}_{n} / \mathbf{V}_{n}$ tem como valor limite o valor $\boldsymbol{\rho}$ (com uma variabilidade aceitável $\boldsymbol{\varepsilon})$, se e somente se:

$$
\left|P-\frac{M n}{V n}\right|<\varepsilon \quad(\mathbf{n} \rightarrow \infty)
$$

Então, $\boldsymbol{\rho}$ é a densidade do material no ponto $\mathrm{P}$, com uma aceitável variabilidade $\varepsilon$, em um limite definido de volume $\boldsymbol{\omega}$. Assim, e da mesma forma, é possível definir o momento dos pontos por unidade de volume (densidade de momento) ou pela energia (densidade de energia). Porém, se a variável de interesse é a força atuando na superfície do corpo, e o valor limite da força por unidade de área existe para cada ponto da superfície, esse limite é denominado tensão, tração ou estresse, e o conjunto das trações ou tensões, em todas as direções da superfície, é conhecido como tensor das tensões ou tensor de Cauchy.

Dada a importância do conceito de tensão, passamos a desenvolvê-lo com maior detalhe. Consideremos um corpo qualquer, por exemplo, uma artéria ocupando uma região do espaço. Imaginemos agora que no interior da artéria possamos limitar uma superfície por uma fronteira, em matemática denominada superfície fechada (Figura 4). Obviamente, algum tipo de interação deverá existir entre o material em ambos os lados dessa superfície. Passemos a analisar um aspecto fundamental dessa interação. Pensemos em uma pequena parte da superfície em questão e a nomeemos de " $\Delta S$ ". Desenhemos, desde um ponto qualquer de " $\Delta S$ ", um vetor perpendicular de magnitude igual a 1 e apontando para fora (vetor normal unitário) que nos permita saber qual é a orientação da superfície. Assim, o vetor nos ajuda a distinguir os dois lados da superfície “ $\Delta S$ ". Por conveniência, deixemos que o lado para o qual o vetor está dirigido seja chamado lado positivo. Consideremos agora a matéria situada no lado positivo de " $\Delta S$ ". Essa exerce uma força na matéria situada no lado negativo de " $\Delta S$ " que denominamos $\Delta \mathbf{F}$. Então, podemos esperar que a magnitude, direção e sentido da força $\Delta \mathbf{F}$ dependa do tamanho e localização da área e da orientação da superfície " $\Delta S$ ". A continuação, permitamos que " $\Delta \mathrm{S}$ " diminua de tamanho até que a razão entre $\Delta \mathbf{F} / “ \Delta S$ " tenda para o valor limite $d \mathbf{F} /$ $d S$. O valor desse limite é uma quantidade vetorial ou vetor, quer dizer, tem magnitude, direção e orientação e a chamaremos de vetor de tração ou vetor de tensão. $\mathrm{O}$ vetor de tensão ou simplesmente tensão representa, portanto, a força atuando em um ponto da superfície e pode ser escrita como:

$$
\mathrm{T}=\frac{d F}{d S}
$$

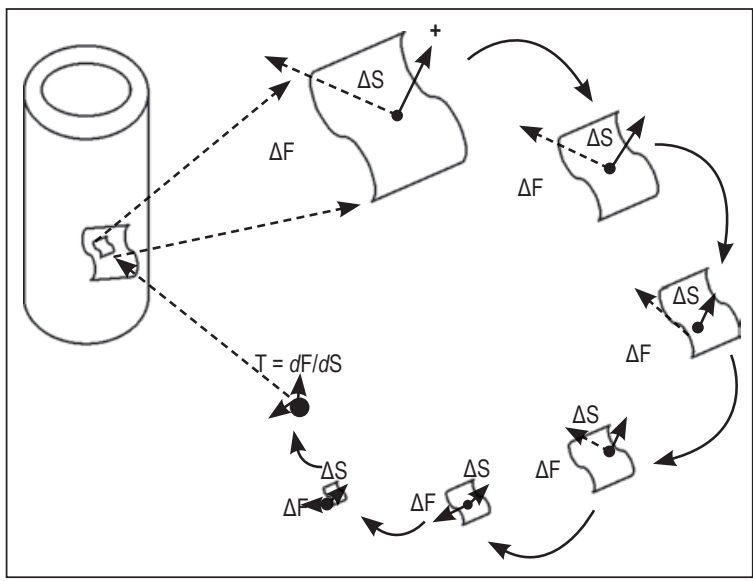

O valor limite $(d F / d S)$ da razão entre $\Delta F / \Delta S$ é um vetor que representa a relação forçalárea, atuando em um ponto da parede arterial, denominado vetor de tensão ou simplesmente tensão.

Figura 4 - Vetor de tensão, tração ou estresse.

A descoberta de que para qualquer superfície fechada "S" de um meio contínuo existe um campo de tensões, cuja ação sobre a matéria que ocupa o espaço situado no lado interno de $\mathrm{S}$ é equipolente à ação da matéria exterior à mesma superfície, é conhecida como o princípio das tensões de Euler e Cauchy. ${ }^{10-12,16,17,43}$ Em outras palavras, na superfície de um corpo, ou na interface de dois corpos, a tensão atuando na superfície deverá ser a mesma em ambos os lados. Isso constitui mais um axioma na mecânica dos meios contínuos porquanto permite definir a interação entre as partes dos corpos.

Desse modo, podemos comprovar que os termos estresse e tensão são usados de maneira intercambiável e, dado que expressam a razão entre a força aplicada e a área de aplicação (relação força/área), sua unidade é a mesma da pressão: o pascal $\left(1 \mathrm{~N} / \mathrm{m}^{2}\right)$. Assim, a tensão pode-se entender como a intensidade das forças que atuam dentro do corpo como reação às forças externas aplicadas (forças de superfície ou contato e de volume ou campo). Para seu estudo, dividem-se suas componentes ortogonais em: shear stress ou tensão de cisalhamento, que corresponde à força tangencial à superfície, e tensão normal ou força perpendicular à superfície (Figura 5). Um tipo de estresse uniforme com o qual nós, médicos, estamos acostumados é a pressão. Um estresse uniforme é uma tensão na qual a força atua igualmente em todas as direções. Porém, 
pode ocorrer a tensão não ser igual em todas as direções (estresse diferencial). $\mathrm{O}$ estresse, em termos gerais, não é fácil de mensurar de maneira direta. Entretanto, como estabelecido pelos axiomas do contínuo, ele pode ser inferido se forem conhecidas as propriedades mecânicas do material (equações constitutivas) e a magnitude do estiramento que condiciona a força aplicada. ${ }^{10}$

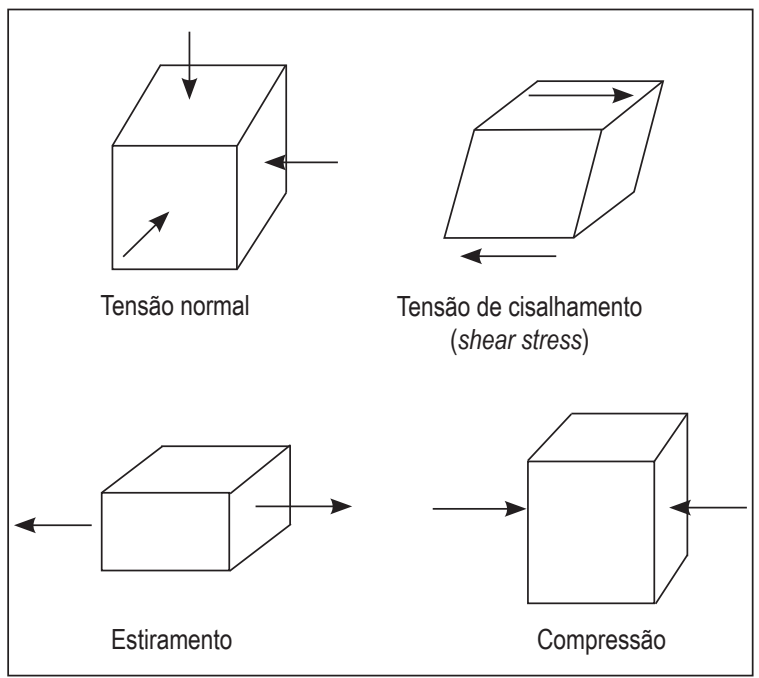

$\mathrm{Na}$ tensão normal, a força atua perpendicularmente à superfície. $\mathrm{Na}$ tensão de cisalhamento (shear stress) a força é tangente à superfície. Observe-se que a tensão condiciona estiramento e compressão, além do cisalhamento.

Figura 5 - Tensões.

Brevemente, pois será tema do seguinte artigo desta série, podemos definir o estiramento como a expressão geométrica da deformação causada pela tensão. ${ }^{10-13,15-17}$, 20,23,31,33,40,43 Portanto, expressa a mudança do tamanho ou da forma. A deformação origina-se quando as partículas ou elementos materiais (moléculas, átomos etc.) que formam o corpo são forçadas a deslocar-se de sua posição original em resposta à tensão. Assim, a tensão ou o estresse está para a força como o estiramento está para a deformação. $\mathrm{O}$ estiramento também pode ser dividido em seus componentes ortogonais: estiramento normal e tangencial com base nas forças que causam a deformação. $\mathrm{O}$ estiramento normal é secundário às forças perpendiculares, ao plano ou à área de secção transversa do material e o estiramento tangencial (shear strain) é causado pelas forças tangenciais à superfície do corpo.

Quando um corpo é submetido ao estresse passa por três sucessivos níveis de deformação: deformação elástica (quando o estiramento é reversível), deformação dúctil (quando o estiramento é irreversível) e fratura (estiramento irreversível com ruptura do material). Assim, os corpos podem ser divididos em duas classes, dependendo de seu comportamento sob tensão: materiais quebradiços (que apresentam uma região de comportamento elástico variável, porém somente uma região pequena de comportamento dúctil antes da fratura) e materiais dúcteis (que apresentam somente uma pequena região de comportamento elástico e uma região grande de comportamento dúctil antes da fratura).

Com base no comportamento do material sob tensão resulta evidente que existem diferentes classes de aneurismas e placas de ateroma. Porém, quais são as bases da diferença entre aneurismas pequenos e placas instáveis, de comportamento quebradiço e aneurismas grandes e placas estáveis, de comportamento dúctil, é uma pergunta que ainda espera por resposta, e estudos de mecânica de meios contínuos são indispensáveis para atingi-la.

\section{Referências}

1. Acevedo-Bolton G, Jou LD, Dispens BP, Lawton MT, Higashida RT, Martin AJ, et al. Estimating the hemodynamic impact of interventional treatments of aneurysms: numerical simulation with experimental validation: technical case report. Neurosurgery. 2006;59:E429-30.

2. Baoshun M, Harbaugh RE, Raghavan ML. Three-dimensional geometrical characterization of cerebral aneurysms. Ann Biomed Eng. 2005;32:264-73.

3. Burattini R, Di Salvia PO. Development of systemic arterial mechanical properties from infancy to adulthood interpreted by four-element windkessel models. J Appl Physiol. 2007;103:66-79.

4. Castro MA, Putman CM, Cebral JR. Patient-specific computational modeling of cerebral aneurysms with multiple avenues of flow from 3D rotational angiography images. Acad Radiol. 2006;13:811-21.

5. Cebral JR, Castro MA, Burgess JE, Pergolizzi RS, Sheridan MJ, Putman CM. Characterization of cerebral aneurysms for assessing risk of rupture by using patient-specific computational hemodynamics models. AJNR. 2005;26:2550-9.

6. Davies PF, Mundel T, Barbee KA. A mechanism for heterogeneous endothelial responses to flow in vivo and in vitro. J Biomech. 1995;28:1553-60.

7. Davies PF, Zilberberg J, Helmke BP. Spatial microstimuli in endothelial mechanosignaling. Circ Res. 2003;92:359-70.

8. Ford MD, Lee SW, Lownie SP, Holdsworth DW, Steinman DA. On the effect of parent-aneurysm angle on flow patterns in basilar tip aneurysms: Towards a surrogate geometric marker of intra-aneurismal hemodynamics. J Biomech. 2008;41:241-8.

9. Frauenfelder T, Boutsianis E, Schertler T, Husmann L, Leschka S, Poulikakos D, et al. Flow and wall shear stress in end-to-side and side-to-side anastomosis of venous coronary artery bypass grafts. Biomed Eng Online. 2007;26:35-9

10. Fung YC. A first course in continuum mechanics. New Jersey: Prentice Hall; 1994. 
11. Fung YC. Biomechanics: circulation. New York: Springer; 1997.

12. Fung YC. Biomechanics: mechanical properties of living tissues. New York: Springer; 2004.

13. Grotberg JB, Jensen OE. Biofluid mechanics in flexible tubes. Annu Rev Fluid Mech. 2004;36:121-47.

14. Han HC, Marita S, Ku DN. Changes of opening angle in hypertensive and hypotensive arteries in 3-day organ culture. J Biomech. 2006;39:2410-18.

15. Holzapfel GA, Weizsacker HW. Biomechanical behavior of the arterial wall and its numerical characterization. Comput Biol Med. 1998;28:377-92.

16. Humphrey JD. Cardiovascular solid mechanics: cells, tissues, and organs. New York: Springer; 2002.

17. Humphrey JD, Delange SL. An introduction to biomechanics: solids and fluids, analysis and design. New York: Springer; 2004.

18. Jankowski P, Bilo G, Kawecka-Jaszcz K. The pulsatile component of blood pressure: its role in the pathogenesis of atherosclerosis. Blood Press. 2007;16:238-45.

19. Jou LD, Wong G, Dispensa B, Lawton MT, Higashida RT, Young WL, et al. Correlation between lumenal geometry changes and hemodynamics in fusiform intracranial aneurysms. AJNR. 2005;26:2357-63.

20. Kassab GS. Biomechanics of the cardiovascular system: the aorta as an illustratory example. J R Soc Interface. 2006:3:719-40.

21. LaDisa JF Jr, Olson LE, Douglas HA, Warltier DC, Kersten JR, Pagel PS. Alterations in regional vascular geometry produced by theoretical stent implantation influence distributions of wall shear stress: analysis of a curved coronary artery using 3D computational fluid dynamics modeling. Biomed Eng Online. 2006;5:40-58.

22. LaDisa JF Jr, Olson LE, Guler I, Hettrick DA, Kersten JR, Warltier DC, et al. Circumferential vascular deformation after stent implantation alters wall shear stress evaluated with time-dependent 3D computational fluid dynamics models. J Appl Physiol. 2005;98:947-57.

23. Li JK-J. Dynamics of the vascular system. Singapore: World Scientific Publishing; 2004.

24. Li YS, Haga JH, Chien S. Molecular basis of the effects of shear stress on vascular endothelial cells. J Biomech. 2005;38:1949-71.

25. Liu YS, Kassab GS. Vascular metabolic dissipation in Murray's law. Am J Physiol Heart Circ Physiol. 2007;292:H1336-9.

26. Martinez TLR, Santos RD, Armaganijan D, Torres KP, Loures-Vale A, Magalhães ME, et al. National alert campaign about increased cholesterol: determination of cholesterol levels in 81,262 Brazilians. Arq Bras Cardiol [serial on the Internet]. 2003;80:635-8. Disponível em : http://www. scielo.br/scielo.php?script=sci_arttext\&pid=S0066-782X2003000600006\&lng=en\&nrm=iso. doi: 10.1590/S0066782X2003000600006.

27. Brasil. Ministério da Saúde. Uma análise da desigualdade em saúde. Série G. Estatística e informação em Saúde. Brasília, DF: Brasil; 2006

28. Murray C. The physiological principle of minimum work: I. The vascular system and the cost of blood volume. Proc Natl Acad Sci. 1926;12:207-14.
29. Murray C. The physiological principle of minimum work: II. Oxygen exchange in capillaries. Proc Natl Acad Sci. 1926;12:299-304

30. Murray $\mathrm{C}$. The physiological principle of minimum work applied to the angle of branching of arteries. J Gen Physiol. 1926;9:835-41.

31. Nichols WW, O'Rourke MF. McDonald's blood flow in arteries: theoretical, experimental and clinical principles. London: Oxford University Press; 2005.

32. Painter PR, Edén P, Bengtsson HU. Pulsatile blood flow, shear force, energy dissipation and Murray's Law. Theor Biol Med Model. 2006;21:3-31.

33. Pena E, Martinez MA, Calvo B, Doblaré M. On the numerical treatment of initial strains in biological soft tissues. Int $J$ Numer Meth Eng. 2006;68:836-60.

34. Qin K, Jiang Z, Sun H, Gong K, Liu Z. A multiscale model for analyzing the synergy of CS and WSS on the endothelium in straight arteries. Acta Mech Sinica. 2006;2:76-83.

35. Rosen R. Optimality principles in biology. Great Britain: Butterworth \& Co. Publishers Ltd.; 1967.

36. Rossitti S. Energetic and spatial constraints of arterial networks. Arq Neuropsiquiatr. 1995;53:333-41.

37. Satcher RLJ, Bussolari SR, Gimbrone MAJ, Dewey CFJ. The distribution of fluid forces on model arterial endothelium using computational fluid dynamics. J Biomech Eng. 1992;14:309-16.

38. Shojima M, Oshima M, Takagi K, Torii R, Hayakawa M, Katada K, et al. Magnitude and role of wall shear stress on cerebral aneurysm: computational fluid dynamic study of 20 middle cerebral artery aneurysms. Stroke. 2004; 35:2500-5.

39. Thompson DAW. On growth and form. United Kingdom: Cambridge University Press; 1961.

40. van de Vosse FN. Mathematical modelling of the cardiovascular system. J Eng Math. 2003;47:175-83.

41. Westerhof N, Stergiopulos N, Noble MIM. Snapshots of hemodynamics. New York: Springer; 2005.

42. Zalba G, Fortuño A, San José G, Moreno MU, Beloqui O, Díez J. Oxidative stress, endothelial dysfunction and cerebrovascular disease. Cerebrovasc Dis. 2007;241:24-9.

43. Zamir M. The physics of pulsatile flow. New York: SpringerVerlag; 2000. p.220.

44. Zamir M. The role of shear forces in arterial branching. $J$ Gen Physiol. 1976;67:213-22.

45. Zamir M. Optimality principles in arterial branching. J Theor Biol. 1976:62:227-51.

46. Zarins CK, Giddens DP, Bharadvaj BK, Sottiurai VS, Mabon RF, Glagov S. Quantitative correlation of plaque localization with flow velocity profiles and wall shear stress. Circ Res. 1983;53:502-14.

Original recebido em março de 2008

Aceito para publicação em setembro de 2008

Endereço para correspondência

Rogelio Iván Ortiz-Velázquez

Av. Dr. Enéas de Carvalho Aguiar, 255- $3^{\circ}$ andar

05403-001 - São Paulo, SP, Brasil

E-mail: rivanov72@usp.br 